\title{
INTEGRATING INTELLIGENT AGENTS \& AHP IN A COMPLEX SYSTEM SIMULATION
}

\author{
Agostino G. Bruzzone, Marina Massei \\ McLeod Institute of Simulation Science Genoa- DIPTEM \\ University of Genoa \\ Via Opera Pia 15, 16145 Genova, Italy \\ Email \{agostino,massei\}@itim.unige.it-URLwww.itim.unige.it \\ Federico Tarone, Francesca Madeo \\ Simulation Team \\ Via Cadorna 2, 17100 Savona, Italy \\ Email \{francesca.madeo, federico.tarone\}@ simulationteam.com-URL www.simulationteam.com
}

\begin{abstract}
This paper provides a general overview about the use of Modeling \& Simulation techniques combined with AHP (Analytic Hierarchy Process) as support to training, planning and decisions making in complex Scenarios (i.e. planning of Food Distribution Points in critical areas affected by natural disasters, large crisis and/or conflicts). One goal of this research is to introduce a new Conceptual Model based on different AHP dynamic criteria depending on units position, warlord presence and characteristics, human behavior modifiers (i.e. fear, trust, anger), mutual trustiness among actors, risk factors; in this model the authors propose to combine simulation and decision support; in fact the paper present a simulation dynamic model driven by IA-CGF (Inte lligent Agents - Computer Generated Forces) developed by the authors; while these agents interoperate with Constructive Simulation the conceptual AHP is used to evaluate alternative and support decision process both of the agents and of the human trainees. In fact AHP approach is a very useful and efficient approach able to support entities in multiple choice evaluation on the field; in fact is critical to proceed in operational planning of e operations such as food distribution considering several parameters and conditions (i.e. capacity in discriminating local population and rebels, attitude profile of warlords, empathy between coalition force and population, etc). So, the intent is to add into IA-CGF the capacity to combine different criteria for finalizing actions and to combine them with human factors and environmental variables, while the simulator allows to quantify and measure the impact and reaction of the population and civilians.

In the first part of the paper it is proposed current the current structure of IA-CGF (Intelligent Agents for Computer Generated Forces) and AHP models; while in the second part, it is proposed an example of food distribution where IA-CGF are driven by AHP methodology in a Simulation framework in order to discriminate alternatives, finalize actions, while interact with the actors involved in a Complex Scenario Evolution. In the third part it is proposed a conceptual model to reproduce food distribution operations' in terms of impact on trustiness and gratitude toward military forces, local authorities and warlords versus evolution of psychological factors such as fear and anger towards rebels or insurgents.
\end{abstract}

Keywords: Simulation, intelligent agents, complex scenarios.

\section{Introduction}

Integration among Modeling and Simulation (M\&S), IA-CGF and Decision Making Techniques is a critical and innovative approach that the authors are investigating for supporting training and operational planning; in fact these techniques are already in use in a wide range of military applications: training, development and validation of new systems, operational analys is.

In military areas (Exercise, Defense Planning, Training and Education, Support to Operations), the importance of $\mathrm{M} \& \mathrm{~S}$ is continuously increasing; in particular today the human behavior modeling is becoming a very strategic aspect considering the necessity to simulate complex scenarios involving civilians and populations that act based on their scenario awareness and emotions, contrary to military units that usually execute orders and task clearly assigned. 
In fact to reproduce these aspects it is critical to model both emotions and rational aspects; until now this consideration are taken into account by involving in simulation experts playing critical roles (i.e. white cell along an exercise to reproduce these elements) or applying pre-defined scripts; therefore it is evident that this is possible in training, but require a lot of efforts in term of preparation and evaluation of many details and interactions; in addition it is very subjective due to the fact that the humans involved evolve themselves while different alternatives are under evaluation and change drastically different teams are involved.

However this problem becomes even more critical in case of operational planning or operation support, in this case the timeframe available to evaluate alternative and the resources on the field don't allow to apply this approach; for these reason it is suggested to substitute many players and activities by creating entities driven by IA-CGF, these Intelligent agents are introduced into Scenario and have assigned high level tasks and missions, that the experts can eventually change dynamically during the simulation run without necessity to go down into details of specific operations and choices; it is critical to outline that until now most of the traditional CGF, even if considered intelligent, was mostly focusing on directing the movement of entities on the map in constructive simulation or in geometry avoidance within virtual environments; therefore the goal of IA-CGF is more related to evaluate the scenario and take decision (i.e. request aid, split, aggregate, avoid contact etc.) based on rules of engagements, unit characteristics and attitudes as well as human factors (i.e. fear, stress, fatigue).

In fact there are many simulation systems effective in supporting training and to develop Computer Assisted Exercises (CAX) and in reproducing joint or single service operations over battlefields, therefore while the scenarios becomes asymmetric and the civilian importance increase, it becomes more complex to identify effective solution able to cover all the required aspects of operations. In fact the introduction of IACGF allows to reduce the efforts and costs to reproduce these scenarios while it is improved the capability to consider multiple interactions in complex systems.

In these models it is critical to [7]:

- Introduce new threats that substitute classical "force on force" engagements, battles, and campaigns; in fact today peace operations, counter-terrorism, counter-narcotics, counter-proliferation, information warfare, or rules and governmental power recover for fledgling democracies and free market economies are becoming more relevant than in the past.

- Introduce new entities that represents Scenario critical actors, very important and active in some specific activity (i.e. CIMIC): by NGO, local and federal authorities, paramilitary organizations, insurgents, guerrilla forces, terrorists, drug cartels, hackers, media warriors, and ethnic or religious mobs.

- Introduce behaviors and characteristics related to psychological and social factors such as religion, cultural background, and humanitarian aspects, fear, stress, aggressiveness.

Due to these facts and in order to simulate complex systems and scenarios rich of variables, it's necessary to define decision process able to be embedded in the intelligent agents to take fast, consistent and rational decision.

It is proposed to use Analytic Hierarchy Process (AHP) as structured technique for dealing with complex decisions related to food distribution and to introduce them into the IA-CGF.

Based on mathematics and psychology, the AHP was developed by Thomas L. Saaty in the 1970s and has been extensively studied and refined since then. This methodology provides a comprehensive and rational framework for structuring a decision problem, for representing and quantifying its elements/nodes, for relating those elements to overall objectives, and for evaluating alternative solutions. 


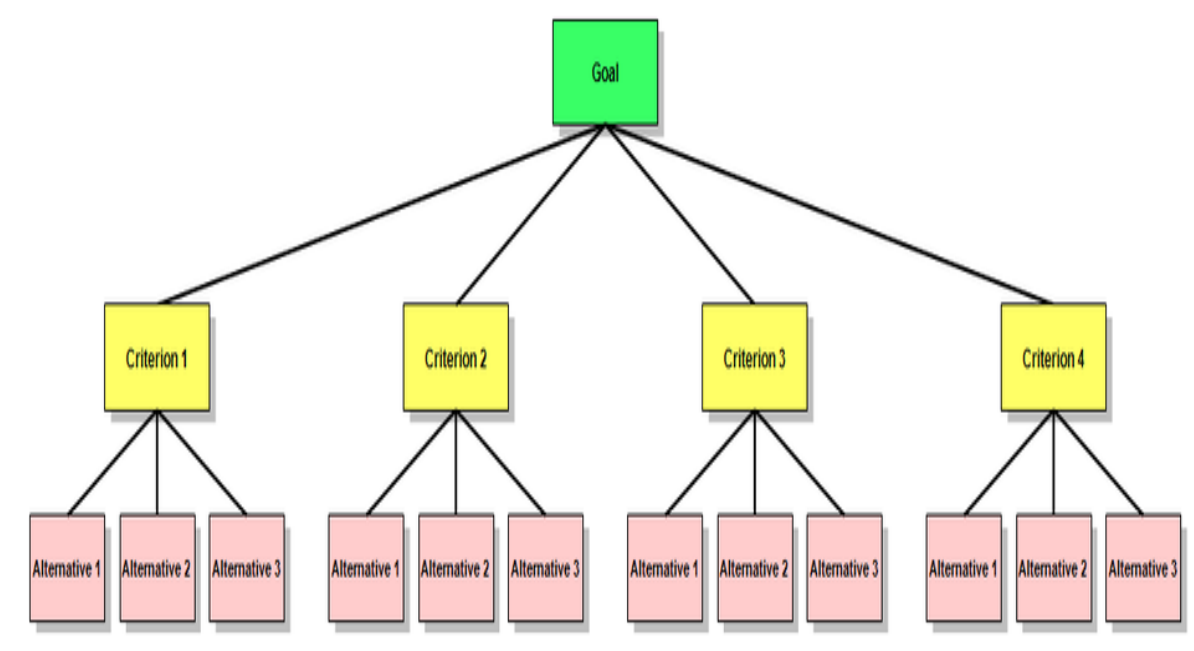

Figure 1. Hierarchical structure.

Rather than prescribing the "right" decision, the AHP allows decision makers find one solution among a set of solutions based on different criteria; by this approach it is possible to obtain a comprehensive and rational framework for structuring the decis ion problem, for representing and quantif ying related elements, for relating those elements to overall goals, and for evaluating alternative solutions.

This approach is applied in many fields such as business, industry, military, education, healthcare, government etc; the authors decided to combine IA-CGF and to use AHP for reproducing the rational thinking, while other models take care of psychological and social aspects. So the AHP approach becomes a decision support for the agents acting in the Discrete Events Simulation. The case proposed in this paper is related to simulate Food Distribution in a scenario devoted to training; in this context it is critical to complete the operational planning of food distribution points including policy definition, modes, locations, etc. In fact, after a Crisis or natural disaster, for instance, a critical de cision on Food distribution is related to the confidence that population have towards the entities taking care of Food distribution or to take care of security in this framework; this scenario represent complex systems that need, usually, to be investigated by simulation models.

For instance the decision to use coalition forces, local authorities, central authorities or NGO (not governmental organization) for providing food/health care support and to decide who is in charge of protecting these operation (or eventually if they have to run without any military/security coverage) strongly affects the population reaction.

Depending on these aspects riots could emerge and so it becomes a fundamental decision to finalize where to activate these actions, how many resource to allocate and what modes to adopt.

\section{State of Art}

The Analytic Hierarchy Process (AHP) is a technique of Multiple Criteria Decision-Making (MCDM). It has been commonly used in industry to aid in concept selection [19].

Due to the following AHP shortcomings related to: the AHP method is mainly used in nearly crisp decision applications; the AHP method creates and deals with a very unbalanced scale of judgment; the AHP method does not take into account the uncertainty associated with the mapping of one's judgment to a number; ranking of the AHP method is rather imprecise; the subjective judgment, selection and preference of decision-makers have a significant influence on the AHP results. AHP is often combined with simulation. In particular due to the vagueness and uncertainty on judgments of the decision-maker(s), the crisp pair-wise comparison in the conventional AHP seems insufficient and too imprecise to capture the decision-maker's judgments correctly and fuzzy logic is introduced into the pair-wise comparison of the AHP to compensate for this defic iency in the conventional AHP [20].

During the same year a study presents an integrated simulation, multivariate analysis and multiple decision analys is for train scheduling. Furthermore, the integrated model was based on Data Envelopment Analysis (DEA) and Analytical Hierarchy Process (AHP) that is hybrid with computer simulation model. The integrated DEA AHP simulation model can be used for selecting optimum alternatives by considering multiple inputs and outputs. First, computer simulation was used to model verify and validate the system 
being studied. Second, AHP methodology determines the weight of any qualitative criteria (input or outputs). Finally, a DEA model is used for solving the multi objective model to identify the best alternative(s) [24]. In 2008, a hybrid approach that combines human judgment, analytic hierarch process (AHP), simulation and a fuzzy expert system for formulating marketing strategies and related Internet strategies was proposed and these techniques and technologies are hybridised by using an intercommunication job-sharing method with human judgment incorporated. Empirical evaluation findings from six managers indicate that the hybrid approach is efficient and effective in supporting and improving both the process and the outcomes of strategy formulation [22].

In 2009 , it was necessary to evaluate the operational capability of the weapon equipment based on combatsimulation, however, the simulation data is so isomerous that it is difficult to make evaluation model. Pointing to this problem, a comprehensive method based on the TOPSIS, AHP and Simulation method (T-AS) was built to evaluate the operational capability of weapon equipment [23].

During last years many experiences highlighted the advantages of the integrative approach of AHP and Simulation above all in term of help to find the efficient solution in simulation context. In fact, during the model development it is possible to determine by AHP variables to be included into model .

At the same time in 2007 it was demonstrated the result of a EDA Project related to Intelligent Agents reproducing civil disorders; the demonstration was based on applying PIOVRA agents into a civil environments by interoperating with a constructive teather simulator creating a multi level scenario, where agents was dealing with town evolution combining paramilitary, military, population and health care units and the constructive framework was simulating strategic planning [3]; in these case the use of G-DEVS/HLA Models was devoted to reproduce the agents structure, while AI (artificial intelligence) techniques was used for softcomputing the emotional and rational behavior and perception of the units [5].

As follow up of this project there was presented RATS (Riots, Agitators, Terrorist Simulators) where warlords and civil disorders models was further extended[]. Currently the authors are developing new CAPRICORN agents devoted to consider not only the parameters related to psychological and soc ial aspects but even to direct these perception among the differnt players (i.e. attribute the fear of some specific event to some of the parties playing the game)[6].

\section{Haiti Model}

The model in use is composed by different objects: comportment objects represent the behavioral model of a group or a organization, while action objects are units on the field; usually the comportment objects have pools of resources that can be used to instantiate action objects that are created with the default characteristics of corresponding comportment objects. The action objects on the field evolve in term of human behavior modifiers (HBM) and attitudes based on the events and actions that experience, in addition their evolution affect back the corresponding comportment object; for instance if the local police is characterized by a mix of attitudes (i.e. hostile 10\%, indifferent $15 \%$, diffident $15 \%$, friendly $40 \%$, confident $20 \%$ ) versus the local warlord a new unit generated to patrol some area will be created with these attributes; by fuzzy allocation matrices the rules of engagements and behavior are applied by each unit; therefore, if for some reason, the local warlord units attack some local police unit, the specific attitudes changes and as feedback even the general profile of the police comportment object could evolve considering the warlord a threats.

The authors define in the model the rules of engagements and the psychological and social parameters of the action and comportment objects at the beginning of the simulation and assign general task and missions.

Each object takes into consideration for succeeding and based on its behavior and attitudes a choice among different alternatives; so they create a structure decomposing decision problem into a hierarchy of more easily comprehended sub-problems/actions, each of which is analyzed independently. The elements of the hierarchy are relate to different aspect of the decision problem, including rational and emotional aspects. Initial parameters estimations, relationships among variables and operational alternatives are defined by subject matter experts or fixed in relation to hypotheses to be tested on different scenarios.

During the Simulation run the objects and their configuration evolve dynamically. The proposed idea it is to define the food distribution planning based on a AHP algorithms that evaluate alternative in the comportment object, based on this approach specific task and orders are assigned at action objects to put in place the proposed mode to distribute food (unit choices, resources to be used, food quantities, distribution point locations, distribution times, operating distribution modes, operating coverage modes) 


\subsection{HAITI Case Study}

The authors developed a special model for demonstrating the potential of interoperable solution for training in a complex scenarios; this scenario was reproducing Haiti Earthquake case (disaster on going in Haiti January 12 2010) is a classical example of very complex system; in this scenario it was created a NotConventional Framework for IA-CGF reproducing the population behavior for "Port au Prince" town before, during the crisis as well as during disaster relief operations; this framework was interoperating with IA-CGF Riots reproducing gangs activities such as loitering, prof iteering as well as demonstration and riots.

Haiti population was generated based on data related to:

- Culture

- Religion

- Ethnic Group

- Parties

- Physiological Aspects (Age, Gender)

The town is divided in quarters and the full real population is generated stochastically (over 2 millions inhabitants) and the related agents are created; the model take cares also of generating the social networks connecting the agents and corresponding to families, work relations and friendship applying consistence algorithms related to the specific scenario and different variables.

The area is divided in Zones, corresponding to quarters of the town in each and to allocate work places, homes to the agents in according with the characteristics of each part of the urban framework.

The food distribution planning includes several parameters such as:

- frequency of the distribution and time (i.e. once per day at 12:00)

- food quantities

- distribution point location

- distribution vector (dropping, trucks, he licopters)

- distribution actor (coalition forces, local authority, NGO)

- coverage (none, coalition forces, local authorities)

Obviously in the Haiti Simulation multiple distribution points need to be setup (in the real case 19 distribution point was organized).

An AHP algorithm is implemented in the IA-CGF Comportment Object representing the entity in charge of Food Distribution in order to properly planning the multiple distribution points location and actors; this algorithm take in consideration dynamically the Zones characteristics; for instance, in this framework, a Zone is modeled in term of:
a. Confidence
b. Security
c. Politeness
d. Warlord Influence
e. Violence Risk

converts these evaluations into numerical values that are processed and compared over the entire range of the problem in order to ranking possible solution and to support finalizing decision on operative modes. A numerical comparison weight between possibilities is derived for each pair of elements all over the hierarchy based on expert (military connections directly involved in Food Distribution, and able to recognize critical points and to support quantifying qualitative variables and assign weight) evaluations taking in consideration each zone characteristic; this approach allow to compare different elements in a rational and consistent way. 


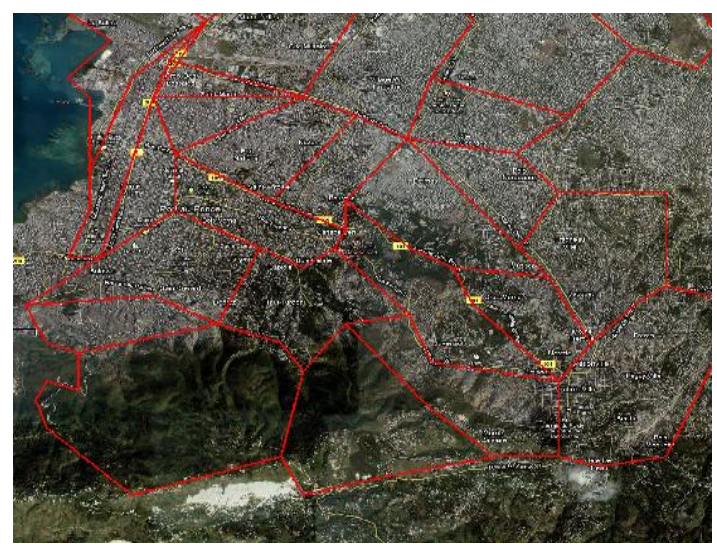

Figure 2. Zone Definition in Haiti Scenario.

Obviously these estimations evolve dynamically during the simulation.

\section{Experimental results on Haiti context}

First of all the authors defined the main objective: to define for each zone, based on several criteria that usually evolve during the simulation, who is in charge for Food distribution among:

- $\mathrm{COA}$ (Coalition)

- NGO (Non Governmental Organization)

- NA (National Authority)

- COA with Escort

- NGO with Escort

- NA with Escort

- Their combination (NA/NGO, COA/NA. etc.)

After defining the main goal the authors proceed with the following steps:

- Definition of the hierarchical structure to be used in order to subdivide the problem in quantitative decision criteria

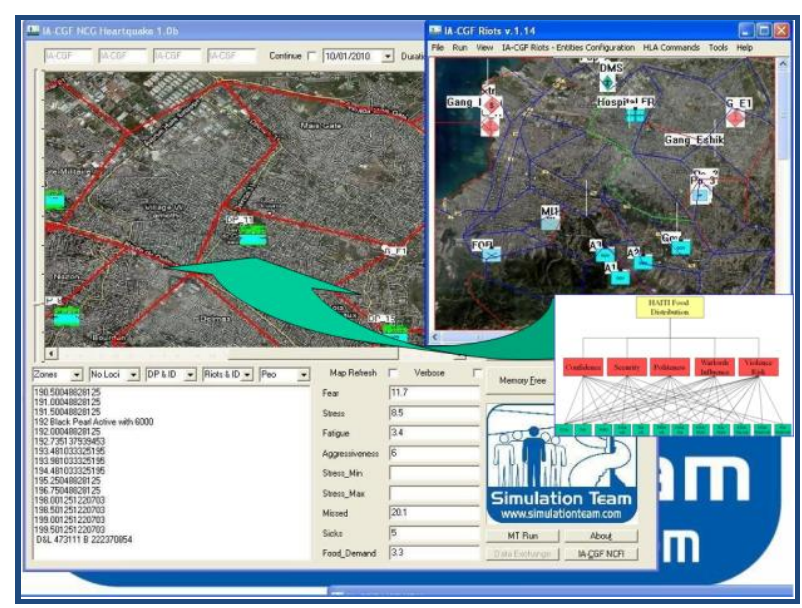

Figure 3. Haiti Food Distribution Structure.

- Define and quantify non quantitative criteria by assigning payload by using Saaty Comparative Importance factors 


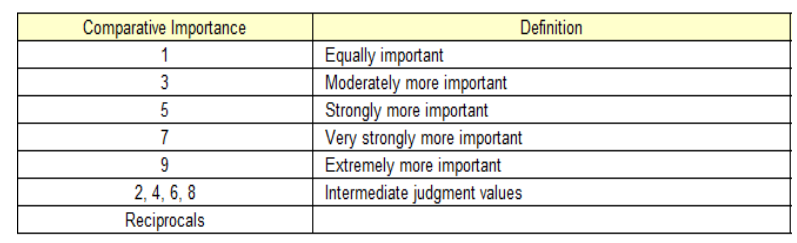

Figure 4. Saaty Comparative Importance.

- For each choice the authors, with support of subject matter expert, evaluated a pair wise comparison in order to define relative importance against the criteria and built the matrix

- Using AHP methodology the authors finalized a priority ranking

\begin{tabular}{|c|c|c|}
\hline COA & $3.00 \mathrm{NA}$ & 1 \\
\hline COA & $1.00 \mathrm{NGO}$ & 1 \\
\hline COA & 1.00 COEwE & 4 \\
\hline COA & 1.00 NAwE & 2 \\
\hline COA & $1.00 \mathrm{NGOwE}$ & 3 \\
\hline $\operatorname{COA}$ & $1.00 \mathrm{COA} / \mathrm{NA}$ & 4 \\
\hline $\mathrm{COA}$ & $1.00 \mathrm{COA} / \mathrm{NGO}$ & 4 \\
\hline $\mathrm{COA}$ & 1.00 NA/NGO & 4 \\
\hline $\mathrm{COA}$ & $1.00 \mathrm{COA} / \mathrm{NA} / \mathrm{wE}$ & 5 \\
\hline COA & $1.00 \mathrm{cOA} / \mathrm{NGO} / \mathrm{wE}$ & 5 \\
\hline COA & $1.00 \mathrm{NA} / \mathrm{NGO} / \mathrm{wE}$ & \\
\hline NA & $3.00 \mathrm{NGO}$ & 1 \\
\hline NA & 1.00 COEwE & 1 \\
\hline NA & 1.00 NAwE & 4 \\
\hline NA & $1.00 \mathrm{NGOwE}$ & 2 \\
\hline NA & 1.00 COA/NA & 3 \\
\hline NA & $1.00 \mathrm{COA} / \mathrm{NGO}$ & 4 \\
\hline NA & 1.00 NA/NGO & 4 \\
\hline NA & $1.00 \mathrm{COA} / \mathrm{NA} / \mathrm{wE}$ & 4 \\
\hline NA & $1.00 \mathrm{COA} / \mathrm{NGO} / \mathrm{wE}$ & 5 \\
\hline NA & $1.00 \mathrm{NA} / \mathrm{NGO} / \mathrm{wE}$ & 5 \\
\hline NGO & 1.00 COEwE & 5 \\
\hline NGO & 3.00 NAwE & 3.00 \\
\hline NGO & $1.00 \mathrm{NGOwE}$ & 1.00 \\
\hline NGO & $1.00 \mathrm{COA} / \mathrm{NA}$ & 1.00 \\
\hline NGO & $1.00 \mathrm{COA} / \mathrm{NGO}$ & 1.00 \\
\hline NGO & $1.00 \mathrm{NA} / \mathrm{NGO}$ & 1.00 \\
\hline NGO & $1.00 \mathrm{COA} / \mathrm{NA} / \mathrm{wE}$ & 1.00 \\
\hline NGO & $1.00 \mathrm{COA} / \mathrm{NGO} / \mathrm{wE}$ & 1.00 \\
\hline NGO & $1.00 \mathrm{NA} / \mathrm{NGO} / \mathrm{wE}$ & 1.00 \\
\hline COEwE & 1.00 NAwE & 1.00 \\
\hline COEwE & $1.00 \mathrm{NGOwE}$ & 1.00 \\
\hline COEwE & $1.00 \mathrm{COA} / \mathrm{NA}$ & 1.00 \\
\hline COEwE & $3.00 \mathrm{COA} / \mathrm{NGO}$ & 3.00 \\
\hline COEwE & $1.00 \mathrm{NA} / \mathrm{NGO}$ & 1.00 \\
\hline COEwE & $1.00 \mathrm{COA} / \mathrm{NA} / \mathrm{wE}$ & 1.00 \\
\hline
\end{tabular}

Figure 5. Pair wise Comparison related to each criteria.

In this Scenario, based on these criteria and related to the specific chosen area the authors implemented the process in the agent; for instance the following combination between NA/NGO supported by Military Escort is proposed for area 6.

\begin{tabular}{l|r|}
\hline COA & 0.001063 \\
\hline NA & 0.0012603 \\
\hline NGO & 0.0172407 \\
\hline COEwE & 0.1154148 \\
\hline NAwE & 0.0850384 \\
\hline NGOwE & 0.0772625 \\
\hline COA/NA & 0.0973446 \\
\hline COA/NGO & 0.1071416 \\
\hline NA/NGO & 0.1071416 \\
\hline COA/NA/wE & 0.1154148 \\
\hline COA/NGO/wE & 0.078321 \\
\hline NA/NGO/wE & 0.1973566 \\
\hline
\end{tabular}

\section{Conclusion}

Figure 6. Example of Results.

The Authors developed special intelligent agents (IA-CGF) to reproduce complex scenarios related to disaster relief and country reconstruction; in addition AHP techniques was used to provide a decision criteria for supporting operational planning on the field to the agents; based on this approach the integration of IA-CGF with AHP Techniques resulted pretty useful, powerful and fast to support both training and 
scenario analysis; in particular for training this allows to investigate effectiveness of different planning decision an polic ies to be activated on the field and to compare trainees choices with agents evaluations.

The simulator developed for Haiti case allowed to evaluate different solutions in contingence and critical situations and to identify feasible alternatives and to rank them based on quantitative analysis based on IACGF actions and their decision process.

\section{REFERENCES}

1. Cinardo G. (2007) “Air Force Research Laboratory, Expert Common Immersive Theater Environment - Research and Development (XCITER\&D) User's Manual Version 1.0", Mesa, Arizona, USA, April

2. Amico Vince, Guha R., Bruzzone A.G. (2000) "Critical Issues in Simulation", Proceedings of SCSC, Vancouver, July

3. Bocca E., Pierfederici, B.E. (2007) "Inte lligent agents for moving and operating Computer Generated Forces" Proceedings of SCSC, San Diego July

4. Bruzzone A., Massei M., Caussanel J. (2006) "Survey current CGF Reporting Current Situation" PIOVRA EDA Technical Report, Genoa, Italy

5. Bruzzone A. G et al. (2004) "Poly-Functional Intelligent Agents For Computer Generated Forces", Proceedings of the 2004 Winter Simulation Conference Washington D.C., December

6. Bruzzone A., Massei M., Brandolini M. "Demonstration for human behavior modeling within civil disorder scenarios".

7. Caussanel J., Frydman C., Giambiasi N., Mosca R. (2007) "State of art and future trend on CGF" Proceedings of EUROSIW2007, Santa Margherita, Italy, June

8. De Felice F., D. Falcone, A. Silvestri, L.Petrillo (2005) "Proposal of a New Decision Making multi criteria Methodology applied to the reengineering of layout in an electromechanical company: the Score Analytic Hierarchy Process", $18^{\text {th }}$ International Conference on Production research, Salerno ( Italy ), 31 July - 4 July

9. Fletcher M., (2006) "A Cognitive Agent-based Approach to Varying Behaviours in Computer Generated Forces Systems to Model Scenarios like Coalitions", Proceedings of the IEEE Workshop on Distributed Intelligent Systems: Collective Intelligence and its Applications,

10. Galula D., (1964) "Counterinsurgency Warfare”, Praeger Security International

11. Galula D., (2006) "Pacification in Algeria 1956-1958", Rand Corporation,.

12. Haugh, B. and Lichtblau, D., (2001) "An Information Tech-nology Support Strategy for PSYOP Impact Analysis," IDA Paper P-3587, Institute for Defense Analyses, February

13. Haugh, B. and Lichtblau, D., (2000) "PSYOP Impact Analysis White Paper," IDA Paper P-3060, Institute for Defense Analyses, August

14. Hue B., EMA/CPCO2J9, (2007) "What Do CIMIC Activities Bring to Stabilization1 Operations", France, Doctrine General Military Review \#12, page 29

15. Kallmeier V., Henderson S., McGuinness B., Tuson P., Harper R., Price S. Storr J. (2001) "Towards Better Knowledge: A Fusion of Information, Technology, and Human Aspects of Command and Control", Journal of Battlefield Technology, Volume 4 Number 1.

16. Lichtblau, D., et al., (2004) "Influencing Ontology," ex-tended abstract in Behavior Representation in Modeling and Simulation Conference

17. Rietjens S.J.H., M. Bollen, (2008) "Managing Civil-Military Cooperation", Military Strategy and Operational Art

18. Nacer A., Taylor A., Parkinson G. (2007) Comparative Analysis of Computer Generated Forces' Artificial Intelligence, Ottawa

19. Thagard, P., (2000) Coherence in Thought and Action, Cambridge, MA: MIT Press

20. Michael J. Scott, (2002) Quantifying Certainty in Design Decisions: Examining AHPASME 2002 International Design Engineering Technical Conferences and Computers and Information in Engineering Conference (IDETC/CIE2002)

September 29-October 2, Montreal, Quebec, Canada

21. Zeki Ayag , (2005) "A fuzzy AHP-based simulation approach to concept evaluation in a NPD environment" IIE Transactions, Sept,

22. Hannu kivijarvi, Markku Tuominen, (1999) "Integrating AHP and Dynamic Simulation:experiences, conceptualizations and business experiments" ISAHP, Kobe, Japan, August 
23. Shuliang Lia , Jim Zheng L. (2008) "Hybridising human judgment, AHP, simulation and a fuzzy expert system for strategy formulation under uncertainty" Westminster Business School, University of Westminster, 35 Marylebone Road, London NW1 5LS, United Kingdom

24. Yin Chun, Huang Yan-Yan, Wang Zhi-Quan (2009) "Topsis-AHP-simulation method and its application in operational capability evaluation" CCDC'09 Proceedings of the 21 st annual international conference on Chinese control and decision conference

25. A Azadeh, S.F .Ghaderi, H Izadbakhsh (2005) "Optimization of Train Scheduling by Integration of DEA, AHP and Simulation" 1st Tehran International Congress on Manufacturing Engineering (TICME2005) 